\title{
Introduction to Sociocybernetics (Part 2): Power, Culture and Institutions
}

\author{
Roberto Gustavo Mancilla \\ LLB. Instituto Tecnológico y de Estudios Superiores de Monterrey, \\ LLM University of California, Berkeley \\ robi357@hotmail.com
}

Table of Content:

Introduction

1. Power
a. Typology of power
b. The exercise of power
c. Dominant coalition theory
d. Viable System Model
e. Epistemology of power: Strategy, conflict and perception

2. Culture
a. Culture as a cosmovision
b. Culture as a process
c. Cultural dynamics

3. Institutions

a. The concept of institution

b. Institutional facts and institutions

c. Institutional transmission

d. Levels of institutional analysis

e. Institutions and power

i. Institutional aspects of power

ii. Epistemological aspects of power: The relationship between organizations and institutions

- Institutional legitimacy

- Institutional Isomorphism

Conclusions 


\section{Introduction}

The purpose of this article is to understand, from the perspective of third order cybernetics, three important and well regarded subjects in sociology and political science: Power, Culture and Institutions.

Regarding the study of power, four questions will be asked: What is it? What is its exercise? Who exercises it? And how it is exercised?

To answer the first, a typology of power will be produced, the second question is answered by means of the distinction between the capacity of doing something and the intentionality that puts it in action, while the third and fourth questions will be answered by means of dominant coalition theory and the viable system models. The model then will consists of the interactions of dominant coalitions within a viable system, which bargain and struggle over the means to use power and which have different forms, like coercion, preferences and cultural setting of power among others.

Culture will be understood as a cosmovision, that is, the way in which a grouping of individuals conceive their environment and themselves in relation to one another, but also the communications that take place in ascertaining the content of such conceptions; that is, culture is at the same time a repository of information and the process in which this information is created or altered.

Institutions are the interplay between Culture, Society and Power, they are the roles that different actors and coaltions have in their search for altering shared meanings and acceding collective resources, they are also the rules and values that inform such process and they are the shared meanings that revolve around power.

\section{Power}

\section{a) Typology of power}

Seen in a general way, power is the capacity to do something, which may or may not be exercised. ${ }^{1}$ It is a force that exteriorizes itself, that is, its effects are felt by someone other than the one that constitutes said force.

Traditional notions of power presuppose a relationship or series of relationships in which one party imposes his will, despite the opposition of others; the problem with these theories of power is that not all acts of power in social relations imply an opposing will. Other aspects of power have to be accounted to have a fuller understanding of power; in his article "The Fourth Face of Power", Peter Digeser analyzes several

\footnotetext{
${ }^{1}$ Searle J.R. (2010) Making the social world, Oxford University Press, 145.
} 
conceptions of power: His first and second faces of power comprise the traditional notion, which he represents by quoting Dahl, Bacharach and Baratz. The third power face of power, represented by Steven Lukes, is the manipulation of the desires and the will of a subject, not necessarily the imposition of an action. The fourth face of power, represented by Foucault departs radically from the other three by stating that it consists in the social construction of the individual, and thus, his idea of power is the cultural foundation of the other three. ${ }^{2}$

In his book Making the Social World, Searle (2010) analyzes the first three notions of power previously reviewed and relates them to his social ontology framework. He states the following:

- The core notion of power is that $\mathrm{A}$ has power over $\mathrm{S}$ with respect to action $\mathrm{B}$ if and only if $A$ can intentionally get $S$ to do what $A$ wants regarding $B$, whether $S$ wants to do it or not.

- Power between human beings is normally exercised through the performance of speech acts. These typically have the illocutionary force of Directives.

- The concept of power is logically tied to the concept of the intentional exercise of power. The specification of the exercise of power therefore requires a specification of the intentional content of that exercise, this is called the "intentionality constraint".

- Another constraint is that of exactness, which consists of knowing who has power over whom and what is it that the power holder makes the power receiver do.

- The threat or the known option of the usage of power, sometimes can be an exercise of power by itself.

Searle (2010) analyzes Foucault's notion of power, also known as biopower, separately and couples it with his notion own in order to explain it by creating what he calls "Background/Network power" ("Background power" in short). While doing this, Searle focuses on the question of whether the "sociological commonplaces" that comprise social construction state cases of power relations.

Foucault's bio-power pervades through society: By means of a "genealogical" account of the development of bio-power, this author states that it is the achievement of control over the bodies of human beings by subjecting them to a series of normalizing practices administered by institutions within the context of social life. To him, biopower is not only comprised of repressive tactics, but it can also be made by

\footnotetext{
2 Digeser, P., (1992) The Fourth Face of Power, The Journal of Politics, Vol. 54, No. 4, 978 and 979.
} 
stimulation. It is pervasive, anonymous, and constant and its scope further broadened and refined by the development of knowledge.

On constructing the notion of "Background power" Searle (2010) reminds the reader that society consists of not just of people and their families but other social entities, and that there are Background practices that are typically shared by them. Without this shared Background, it is hard for a society to function; therefore, social pressures can be a form of power. This is because the Background and Network, as defined by this author are a set of norms of behavior, that if violated, are enforced on the infractor by a series of sanctions, which can range from: expressions of disapproval to strong forms of ostracism, contempt, hatred, derogation, and even violence.

The knowledge of the possibility of the enforcement of such penalties is an unconscious exercise of power within the confines of the constraints created by Searle (2010) and the intentional content of this act is "Conform!" The exactness constrain is overcome because in this type of exercise of power, anyone can exercise power over anyone.

When the Background and Networks function in the exercise of power mechanisms they function as standing Directives because they tell each member of the society what constitutes appropriate behavior and what not. This form of social control are generally imperceptible by those subject to it because generally people does not tend to doubt their presuppositions, attitudes, dispositions and practices.

\section{b) The exercise of power}

As it was said in prior paragraphs the basic nature of power is not only a command or an imposition; rather it is the capacity to act $^{3}$. If it is taken that power is capacity, then the following question must be answered: What directs that capacity? What is its purpose?

To answer this, it is necessary to bring forth the before mentioned notion of intentionality and its collective variant, which act as a complements. This is what causes the power to be implemented, what sets it in motion and gives it a meaning, a purpose. When this happens, there is an exercise of power, but because the notion of power carries with itself certain mysticism, it would be better to denominate it capacity. In this manner, one can speak of an exercise or usage of capacity.

\footnotetext{
${ }^{3}$ I had advanced on my book Derecho adjetivo constitucional, for a similar structure, although my notion of "intention" was quite unrefined as I had not come with the idea of intentionality and I had not also found Searle's treatment of power, which I find akin to my own, although his is in some aspects better structured. See Mancilla Castro R.G. (2012), Derecho adjetivo constitucional [Constitutional adjective law], NOVUM.
} 
There is a close relationship between capacity and intentionality, which has caused that many authors conflate them in the notion of political power. What most authors have understood as power is the usage of capacity; "power" is just one element of the mentioned exercise. This was perfectly understood by Searle.

To further this confusion, in several languages power can be understood as both a verb and a noun. As a verb it is the faculty or potency to do something and as a noun it is the faculty, authority that someone possesses to do execute or order something. ${ }^{4}$ Although veiled, to conflate this difference leads to a similar conclusion to those held by traditional authors.

Another important aspect regarding the exercise of power is that capacity has its limits: it must be congruent with the finality that intentionality imposes on it. In the diverse interactions that can exist in an environment, one intention can impose itself over another or it can be frustrated by physical impossibility. It can be presupposed, although totalitarian states are an exception, that the goal of society is the achievement the collective good.

The content of the concept can vary among the different ideologies that consider society as an end and not as a mean, but one common theme is the fact that this goal is constantly renewed, because of the continued existence of humans.

On this understanding, the fulfillment of these goals form the space that exists within the capacity of Society and its application. However, the intentionality and its subsequent resources of a polity can be frustrated and subjugated, be it by means of the usage of capacity of another polity o by a representative sector of the people, by an individual will or by a non representative sector of individuals.

Of this it can be said that there can be three types of intentionality with respect of an exercise of power in society: a collective that represents all of society, a social that encompasses non representative sectors of society and an individual, all of which coexist and struggle with one sometimes winning over the other.

It was said in prior paragraphs, there is a usage of capacity when there is an intentionality that puts in motion a capacity of action, which results in an act that transcends its creator. When said action, not being frustrated by an outside intentionality or by a material impossibility achieves its goals then there is a materialization, which consists in the manifestation of the goal that the subject had set for himself and for

\footnotetext{
${ }^{4}$ Although it is not the case for the Oxford Dictionary in the English language, in the Royal Dictionary of the Spanish Language (http://buscon.rae.es/drael/SrvltConsulta?TIPO_BUS=3\& LEMA=poder) and in the French Dictionary of the Language (http://atilf.atilf.fr/dendien/scripts/tlfiv5/visusel.exe?11;s=1303 $544445 ; r=1$;nat=;sol=0;) power is a verb and a noun in the ways described.
} 
which it had put its resources in motion, it is the materialization of the usage of capacity.

For materialization to occur there must be structures that help join both intentionality and capacity, these are called capacity conducting structures. Applied to a general notions of society, these structures center on two fundamental aspects: How do you exercise capacity? And by means of whom? The first question is circumscribed to the methods used to achieve the goals of society, while the agents used by it in the attainment of this end comprise the second aspect.

What can be understood as a capacity conductive structure? Conductive structures are the nexus between capacity and intentionality and allow the materialization of intention and the directing of power. They are a set of institutional facts, that is, objects and people upon which a status function is bestowed towards the achievement of certain purposes. So to create these structures, collective intentionality is used, therefore, in the formula "X counts as $\mathrm{Y}$ in context $\mathrm{C}$ " the $\mathrm{Y}$ can be the $\mathrm{X}$ of another usage of collective intentionality.

The structures that center on "how" must focus on creating a know-how, a methodology, while those of "who" must create an organization schematic regarding the policy to be implemented. These two aspects are complementary, for one determines the way that the agents of society, that is, those that have status functions to act on its behalf must act, and the other constitutes the knowledge and procedures by which society looks to achieve its end.

These structures either tend towards intentionality or capacity: A structure centered to "who", tends more towards capacity, for it refers to the human element that looks to carry out the set goal. On the other hand, the structure of "how", tends towards intentionality, for there is the determination of how to achieve the objective.

An interesting case regarding conductive structures is found in the legal structure of society, because as it is an element that organizes it and allows the regulation of its behavior due to its applicability and the creation of the organs that can exercise capacity. Within this classification, the normative order can be both a structure of who and how, depending on what is regulating. In summary, the legal order is the structure or the capacity conductive structures.

For society to use its resources there is a need for capacity and intention, and also of structures that can lead to the attainment of a set goal. This can be illustrated in the following way: 


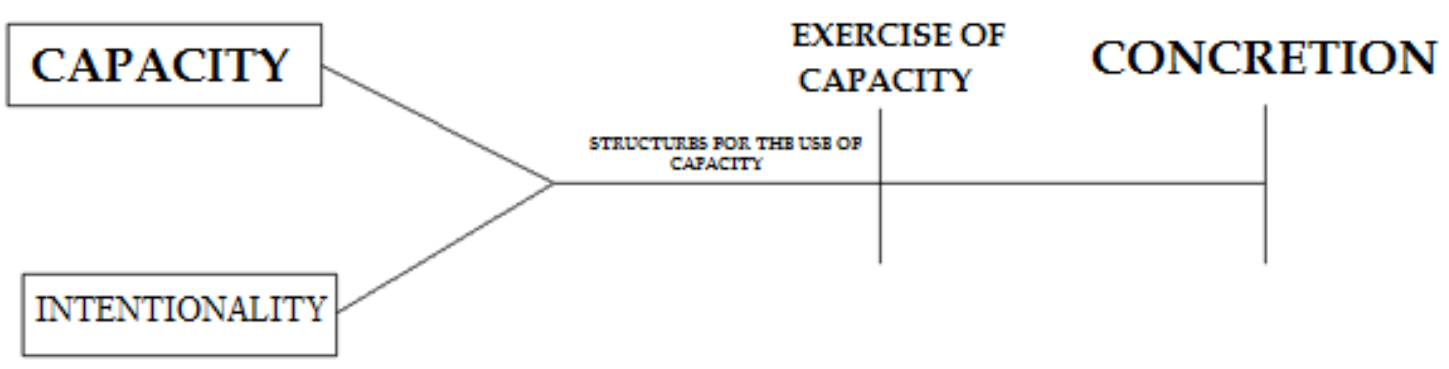

Within the context of exercise of capacity, two of the ideas of Loewenstein can be of use: first, the notion that to put capacity in motion implies the creation and implementation of policy, and the idea of creating subjects of policy: the makers and implementators, and the receivers.

\section{c) Dominant coalition theory}

Robert Dahl opens his book "Who governs? Democracy and power in an American city" with the following statement: ${ }^{5}$

In a political system where nearly every adult may vote but where knowledge, wealth, social position, access to officials, and other resources are unequally distributed, who actually governs?

That is, where capacity and the way to implement it is unevenly distributed, how is power exercised? Helpful to respond this question is Cyert and March's dominant coalition theory, which was created within their theory of the firm as a way to show how they determine their goals. Within the context of power, this theory can be used to determine the way social systems set their own goals.

Cyert and March (2012) depart by stating the problems entailed within a theory of collective goal determination: ${ }^{6}$

- People have goals, collectivities of people do not.

- Collective decision making requires the implementation of an analogy of individual goals at the individual level.

These authors view the organization as a coalition of individuals, which can be organized into subcoalitions. The borders of the coalition are never permanently set and

${ }^{5}$ Dahl, R. (2005) Who Governs? Democracy and Power in an American City, (2nd ed.) Yale University Press, 2.

${ }^{6}$ Cyert R.M., March J.G. (2012) A Behavioral Theory of the Firm, (2nd ed.) Blackwell, 31. 
they can be redrawn on temporal or functional criteria. However, they also signal a contradiction between the idea of organizational goal and the idea of the organization because coalitions have potential for goal conflict within the process of determining collective goals.

Cyert and March (2012) also state the three main procedures by means of which the objectives of a coalition are determined:

- The bargaining process by which the composition and general terms of the coalition are fixed.

- The internal organization process control by which objectives are stabilized and elaborated.

- The process of adjustment to experience by which coalition agreements are altered in response to environmental changes.

Another relevant aspect of dominant coalition theory is that of side payments, which can take various forms: money, personal, treatment, authority, organization policy, among others. When a winning coalition bargains with itself over side payments, organizational objectives arise and are clarified.

However, the agreements on the side payments are imperfect, because they cannot foresee all future circumstances. The participants of the bargain have incentives to operate under the framework created by it and to create systems that will enforce it, examples of this are the budget and allocation of functions. Also, secondary bargaining regarding these controls can help to specify and elaborate the initial agreement.

Past experience matters for bargaining in the coalition: Past agreements, be them primary (initial agreement) or secondary set precedent for current situations and for future disputes and tensions. The demands of member of the coalition are disorganized and influenced by past situations. These do not receive attention evenly, and they can conflict one with the other, and also, the focus on certain demand can vary: adverse experience can influence the focus on a demand, as well as solutions to current problems.

A coalition is viable if the payments to its members are enough to keep them in the group, when these payments exceed the requirement of cohesion, there is organizational slack. Although all participants receive slack, the distribution is not equal, and it is useful in adverse times because it acts as a cushion.

The what and the who of power relate in the following way: The competition among the coalitions that form part of a social system constitutes the intentionality element of the exercise of power model advanced in past paragraphs. By itself is an exercise of power, that constitutes a further collective exercise of power. The nature of this model, like that of the Viable System Model that will be studied on the next topic is recursive. 
The structures that conduct power can range from budget and allocation of functions, which allow the renegotiation of the initial bargain, to things like money, property and other institutional facts, which constitute the things bargained as side payments. They are conductive structured towards the how, because they help state the terms of the bargain and the cooperation towards dominating other coalitions.

Within the bargaining process the usage of power in the form of various resources is negotiated: Be it the capacity of forcing someone do something against their will or abstaining to do something, manipulating preferences or having influence the cultural context on which power is exercised. On this matter, it must be noted that the Background that surrounds the exercise of power is both an institutional constrain, but it can be reconfigured by those who exercise power.

\section{d) Viable System Model}

Once the holders of power and its means of exercise were analyzed, it is necessary to lay down a frame that can encompass their organization in their usage of power. This will be achieved by means of the Viable System Model created by British cybernetician Stafford Beer (2012) in his classic book The Brain of the Firm. He applied this model to the Chilean economy, while working as a consultant for President Salvador Allende in what became known as Project Cybersyn or Synco. ${ }^{7}$

In it he creates an analogy of the human brain, to him "an organization is viable if it can survive in a particular sort of environment", 8 this means that viable systems are teleonomical because their goals are set by their surroundings; the viability of any system consists in maintaining its identity separate from its surroundings.

When interacting with its environment, a system seeks homeostasis, the "stability of a system's internal environment, despite the system's having to cope with an unpredictable external environment". And to achieve such a state it must deal with variety, which is "a measure of complexity: the number of possible states of a system".

Of great importance is also the Law of Requisite Variety, also known as Ashby's Law, which states that "only variety can absorb variety". This means that a system must amplify its own variety or attenuate that of its environment in order to have a similar level and thus achieve homeostasis.

The idea of viable system is compatible with the notion of third order cybernetics, because it copes with variety is by means of communication, which entails, language, information, speech acts and a Network and Background of existing social ontology. It

\footnotetext{
${ }^{7}$ Beer S. (2012) Brain of the Firm, (2nd ed.) John Wiley and Sons.

${ }^{8}$ Beer S. (2010) Diagnosing the System for Organizations, John Wiley and Sons, 1.
} 
can even be said that Stafford Beer, by advancing this model and also the notion of Management Cybernetics, is one of the precursors of third order cybernetics.

In social viable systems are recursive, that is, they contain viable systems (which are human beings) and they are contained within other viable systems. ${ }^{9}$ The Viable System Model is comprised of five subsystems, which handle different functions and complement each other in order to have coherence .

System 1 is in charge of the fundamental operations within the viable system, which is known as implementation. It comprises all the operations which justify the existence of the system, but it does not include the functions of senior management or officials. Livas (1988) notes that the internal functioning of this system equals the total internal functioning of the whole system. System 1 is always a viable system by itself, that is, it is its own beginning and end; this is why the recursion of a viable system is important.

When System 1 in its attempt to reach homeostasis overcorrects itself, it incurs in oscillation, System 2 is in charge of dampening it. That is, this system is in charge of balancing System 1, and when it is missing, systems can be close of disintegration. System 2 is then in charge of coordinating one or more 1 and there can be a plurality of it because of the different oscillatory sources.

The function of System 3 is to handle the day to day activities of the viable system, which include the supervision of the anti-oscillatory functions of System 2. It is also responsible for replenishing necessary variety when the latter has been filtered out by the managerial activities of the lower systems; this is done by procedures like audits, work studies and taskforce activities. System 3 can be of two types: System 3, which is in charge of the directing functions of the day to day, and System $3^{*}$, which is in charge of replenishing the existing variety by means of auditing and other procedures already mentioned in the last paragraph.

The internal processes of the Viable System are dealt by the communication between Systems 3-2-1, Beer calls these activities "the inside and now of the organism".

System 4 is in charge of the long term planning and development functions of the viable system. Because of the recursive nature of the Viable System, to operate 4 requires the creation of a model of itself and also enough freedom to learn, adapt and evolve by means of the simulation of reality. This system also provides self-awareness for the System in focus.

System 5 controls the identity of the viable system and is in charge of the defining its objectives, that is, it is the political component of the system. It intervenes between the activities of Systems 3 and 4, which might not share the same priorities and helps to conciliate them.

\footnotetext{
${ }^{9}$ Livas J. (1988) Cibernetica, Estado y Derecho [Cybernetics, State and Law], Ediciones Guernika, 159.
} 
As a recap, Livas(1988) states that Systems 3, 4 and 5 engage in different types of planning, which distinguishes them from one another and also helps to understand their interaction and dynamics. System 3 is in charge of tactical or programmatic planning, which is that concerning the day to day. System 4 handles long term planning, while 5 states the values that the system pursues, therefore incurring in normative planning.

Together, Systems 3, 4 and 5 constitute the "outside and then" function of the Viable System, because they are in charge of handling the interaction of the system with the environment. That is, these systems form a metasystem which is "over and beyond" systems of lower logical order.

In the case of the Viable System Model, the conductive structures of power that focus on who wields it are the infrastructure and resources that allow each system to accomplish their function. This apply both to the "internal" function carried by Metasystem 1,2,3 and the "external" executed by Metasystem 3,4,5.

Regarding the exercise of power, System 1, by making the activities that are fundamental to the viable system is the one that exercises power in all of its senses, this activity is modulated and lead by the other systems with the anti-oscillation and planning functions. Also, returning to the idea of the recursiveness of power, within the organization of the system are exercises of power which determine the way its functions are carried on.

Background power has a double interaction with the Viable System Model. First, the existing culture and institutions on the exercise of power both constrain and empower System 1 and can be influenced by it. But also, the functions of System 5 consist of the determination of the identity of the System by cultural means, which includes Background power.

\section{e) Epistemology of power: Strategy, conflict and perception}

The idea of power in all its configurations takes place in an environment of conflict: it presupposes the access of power, its usage, its maintenance, the way the spoils are shared within the ruling coalition. At the same time the idea of conflict presupposes a distinction between the individual or the coalitions that seeks power and those other that contend for it; that is, a distinction of "us" and "them".

Seeing that conflict is the context within which power is developed, the idea of strategy must be put forth in order to understand how an individual or coalition can reach the goal of reaching from its current state or keeping power; a strategy is a plan of action that is used to achieve a goal and which purports an efficient usage of resources in such endeavor, they are implemented by means of tactics, which are tools subordinated to the goal, and which in turn consist of several concrete actions. 
From the inclusion of strategy and tactic to the search and maintenance of power stems a very important conclusion: Every political structure created is and has been structured like a game, the latter understood as structured playing that possess rules, challenge, goals and an interaction stemming from these three. There are two goals within any basic strategy: remaining a viable coalition or individual and achieving the goal; that is, maintaining the structure and setting and reaching a goal.

Political games will require sometimes direct confrontational strategies on one hand and indirect influencing on the other; the selection of these types of tactics will depend on the nature of the circumstances and of the players, for the latter can be individuals, private corporations or governmental or international entities, which will be enabled and constrained to strategize by their own structure and resources.

Knowing about power is a subjective endeavor in which a human cognitive system accommodates information to its cognitive domain or viceversa, attempting to construct an image of how much power do the power holders possess, while being also bound to unconscious processes of normalization by means of social rationality. Learning of power is an extension of knowing in the sense that a conversation of sorts is created by the participants of the political process by means of their forming of alliances and their actions towards one another and the respective feedback and perceptions, all in order to achieve dominance. On this interaction two basic rules can be extracted: 1) Improvement can be attained by facing more experienced opponents 2) Complex environments will yield sophisticated players.

\section{Culture}

Selznick and Broom (1981) define culture as the "shared ways of thinking and believing that grow out of group experience and are passed from one generation to the next"; ${ }^{10}$ culture can then be understood as both a repertoire of habits, information and perspectives, that is, a cosmovision; and as the constant process of creating and changing the existing repertioire. In both of these aspects culture has an intimate relationship with language, for it is the vehicle that allows social ontology and as a consequence culture. It enables the transmission of culture between subjects and the creation of vehicles by means of assignation of functions and deontic powers. It also enables subjects to create and recreate it by means of cognitive exchanges and communications based on signs. However, language is not only a vehicle for culture, but it also changes and shapes it.

\footnotetext{
${ }^{10}$ Selznick P., Broom L., Broom Darroch D. (1981), Sociology, (7th ed.) Harper and Row, 54.
} 
Because of its basis on language, culture pervades into every social structure and every aspect of social life; it even influences individuals, because it serves as a background on which they are developed and because they are a medium upon which they react. Because of this it can be found within subjective and geographical levels of societal analysis.

\section{a) Culture as cosmovision}

When it comes to culture as a cosmovision, it can be understood as a series of signs that function as common ground between individuals for their communication, as it constitutes what Searle calls Network and Background. Culture as a cosmovision can be contained within institutional facts and be expressed through the following vehicles:

- Symbols: It is an object that has a specific meaning. They are institutional facts.

○ Referential: They are reference to specific meanings.

- Expressive: Are more broad and tend to embody values and ideals.

- Values: It consists of a widely held view of something that is important to the collectivity.

- Moral norms: They are values expressed through rules of behavior that are sanctioned by disapproval and sometimes even violence.

○ Mores: The most important cultural norms.

○ Folkways: Weaker norms.

Culture as a cosmovision attempts to be a cohesive agent that enables communication between its users; and again, different levels of analysis can have their vehicles interacting with those of other levels. Sometimes, when an individual faces a culture that is significantly different from his own, he experiences cultural shock; subcultures can also develop within levels of societal analysis.

\section{b) Culture as a process}

As a process culture is the convergence between Searle's social ontology and the groupal and social levels of rationality, this relationship is expressed in three ways: 1) Social ontology is used to establish, maintain and renew the content of culture in some groupal or societal level; 2) Groupal and societal levels of rationality interact between them by means of social ontology; 3) In such interactions, levels of rationality have certain resistance to drastic change and will attempt to normalize their subjects. Culture as a process starts with the inception of a cultural pattern or the latter's modification, 
afterwards it is transmitted and if it is successful, it results in widespread adoption, although some patterns can fall into obsolescence. This can be visualized as follows:

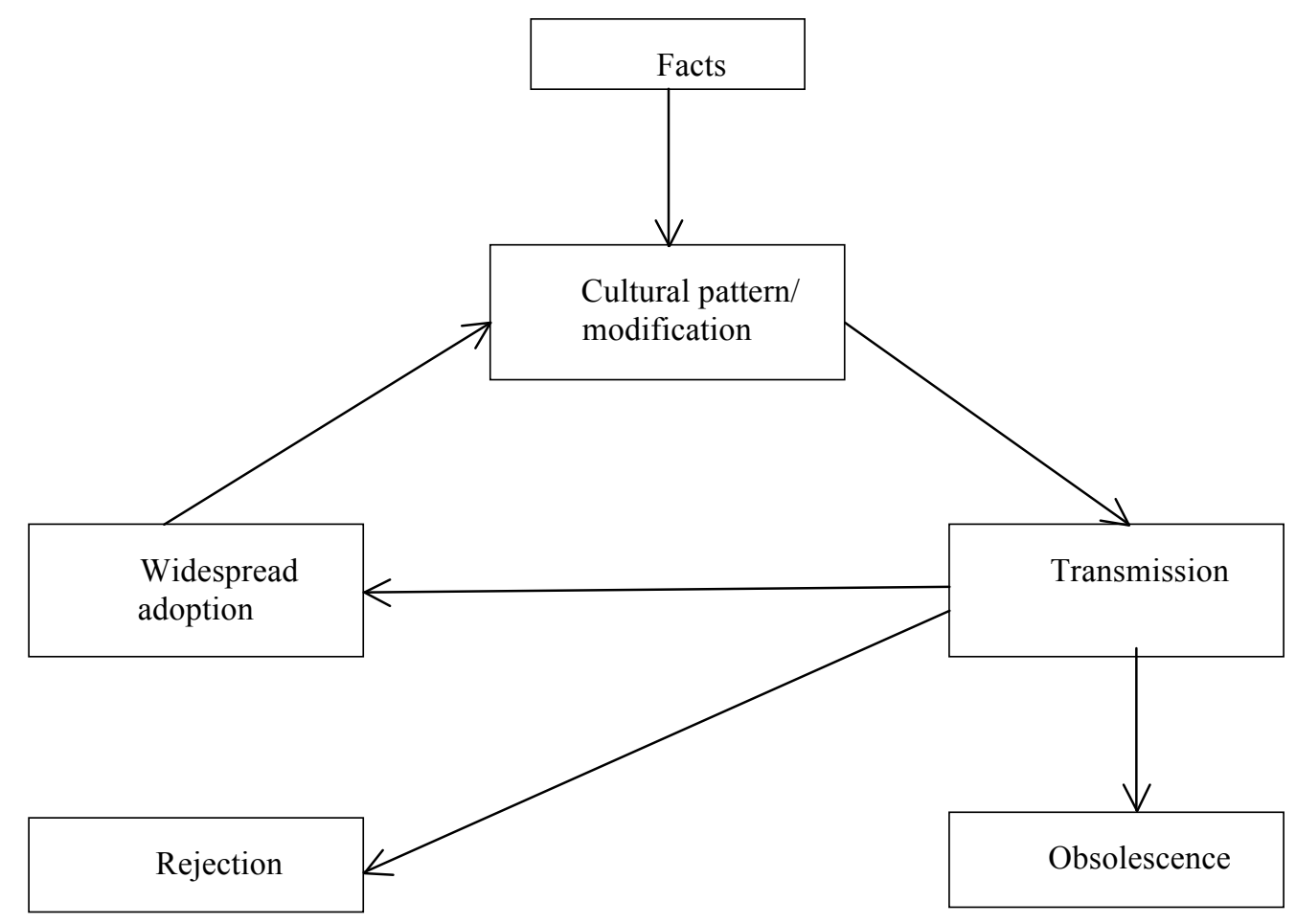

Diagram 1: Culture as a process

As a process of creation and change, culture can manifest itself in different ways:

- Acculturation: It is the adoption of new traits and patters resulting from the interaction with another culture.

- Weakening: It is the change in the vehicles that entails a loss of viability within the established framework.

- Renewal: A culture can change when it is subject to new values, resulting in a restructuration of the existing cosmovision.

- Destruction: Some times change or external influences result in the weakening and the collapse of the cosmovision. 


\section{c) Cultural dynamics}

The process of creation and modification of culture and the dynamic and changing nature of human beings guarantees the existence of variation; however, as it is both a process of communication and it is carried out by individuals, there are also similarities between cultures, referred to by Selznick et al. (1981) as cultural universals:

- Psychic unity: There are similarities between human beings in their subjection to conditioning, feelings, and expectancy of order, among others.

- Requirements of group life: Certain requirements need to be fulfilled in order to guarantee the viability of a collectivity; the solutions to problems faced are discovered once and again.

- Limited solutions: Human action is made within physical and environmental limits.

- Selective adjustment: Each culture select the means and ends to its needs.

Despite the commonalities between cultures, it is not uncommon that each group views their perspective as the natural one, eschewing those different from itself; this is known as ethnocentrism. This view finds its counterpart in the notion of cultural relativism, which encourages tolerance and understanding towards foreign ways.

\section{Institutions}

\section{a) The concept of institution}

To Scott (2008) "Institutions are comprised of regulative, normative and cultural cognitive elements that, together with associated activities and resources, provide stability and meaning to social life". ${ }^{11}$ This notion is initially incomplete because it does not specify the content of the elements that comprise it, however, they will be explained in the following paragraphs, but before taking this endeavor a list of general features of institutions will be issued:

- Permanence: They can be maintained and reproduced and therefore withstand the passage of time.

- Degree of Inertia: They can resist change.

- Transmissibility: They can be passed from generation to generation.

- Influence: They can constrain, empower or guide the behavior of actors.

- Manifestation: They can be contained within different media.

\footnotetext{
${ }^{11}$ Scott W. R. (2008) Institutions and Organizations, Sage, 48.
} 
The regulative element of institutions is a system of formal or informal rules, backed by coercive power with the goal of influencing and constraining human behavior to achieve stability and reduce uncertainty. Like the regulative, normative systems have a system of rules, but unlike them, they are also a set of values: "Values are conceptions of the preferred or the desirable, together with the construction of standards to which existing structures or behaviors can be compared and assessed... Normative systems define goals or objectives, but also designate appropriate ways to pursue them".

The third element of Scott's (2008) notion of institution stresses the importance of "the shared conceptions that constitute the nature of social reality and the frames through which meaning is made". Cultures are not unitary systems, they are subject to change and certain meanings can be contested; the cultural cognitive element signals the influence of cultural templates and patterns of action in the behaviors of actors, much like Foucault's notion of power. Also, unlike norms, cultural cognitive institutions stress the socially mediated construction of a common framework of meaning.

The three conceptions of institutions are part of a continuum that transits between conscious (rational and normative) to unconscious (cultural-cognitive), from legally enforced (rational and normative) to taken for granted (cultural-cognitive). The interaction between them is mutually influencing and dynamic, that is, depending on the situation and the passage of time; varying combinations of elements can prevail, although sometimes a specific notion will acquire primacy. However, they can also diverge by supporting differing choices and behaviors, having as consequence both instability and confusion and the opportunity for change. This can be expressed by means of this diagram:

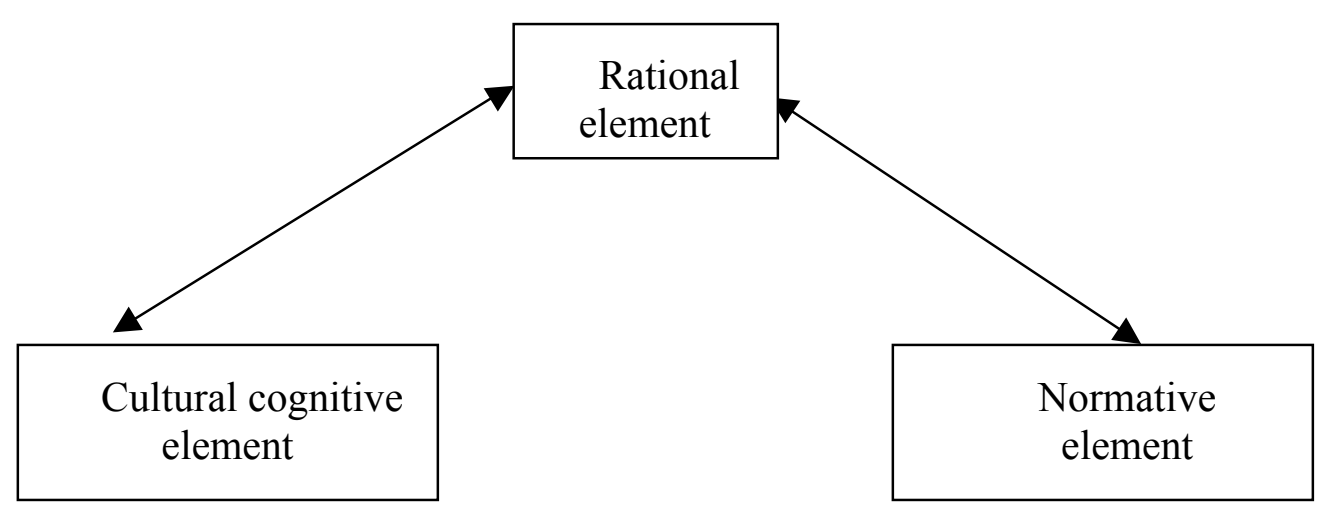

Diagram 2: Conceptions of institutions 
Institutions then can be understood as a set of norms, values, and cultural scripts, patterns and shared meanings that constrain, empower and guide the general and specific behavior of actors and together have as a goal to provide stability and meaning to social life. Institutions are the convergence of Society, Power and Culture; the interaction between the three elements of institutions can be stated in the following way:

\begin{tabular}{|c|c|c|c|}
\hline Basis of \\
compliance & Expedience & Social obligation & $\begin{array}{c}\text { Cultural- } \\
\text { Cognitive }\end{array}$ \\
\hline Basis of order & Regulative rules & $\begin{array}{c}\text { Taken-for- } \\
\text { grantedness }\end{array}$ \\
\hline Mechanisms & Coercive & Normative & $\begin{array}{c}\text { Shared } \\
\text { understanding }\end{array}$ \\
\hline Logic & Instrumentality & Appropiateness & $\begin{array}{c}\text { Constitutive } \\
\text { schema }\end{array}$ \\
\hline Indicators & $\begin{array}{c}\text { Rules, Laws, } \\
\text { Sanctions }\end{array}$ & $\begin{array}{c}\text { Certification, } \\
\text { Accreditation }\end{array}$ & $\begin{array}{c}\text { Orthodoxy, } \\
\text { Common beliefs, } \\
\text { Shared logics of } \\
\text { action, Isomorphism }\end{array}$ \\
\hline $\begin{array}{c}\text { Basis of } \\
\text { legitimacy }\end{array}$ & $\begin{array}{c}\text { Legally } \\
\text { sanctioned }\end{array}$ & $\begin{array}{c}\text { Morally } \\
\text { governed }\end{array}$ & $\begin{array}{c}\text { Comprehensible, } \\
\text { Recognizable, } \\
\text { Culturally supported }\end{array}$ \\
\hline
\end{tabular}

Diagram 3: Institutional interactions

\section{b) Institutional facts and institutions}

Institutions whether manifested as norms, values or cultural scripts or patterns are institutional facts; they are the result of the assignation of function to an object or a set of individuals, as such, new institutions can be created, their meaning is subject of change and even ignored by the population. In the latter case, an institution can collapse when enough people decline to assign a function and meaning to it and even change it for another. A prime example of this is cigarette currency; in countries where currency was debilitated, cigarretes can become an accepted mean of exchange, such as the case 
of Germany after the fall of the Third Reich ${ }^{12}$ or Russia in the midst of the fall of Communism.

Aspects of Society, Power and Culture converge in the idea of institutions by means of the usage of speech acts and institutional facts; institutions withstand the passage of time by the tacit acceptance and widespread usage of generations and generations of a population. Because the creation of institutional facts implies a cosmovision manifested as a series of common background and shared values it can be used to constrain and empower behavior and to a degree, they resist change. Finally, the formula " $\mathrm{X}$ counts as $\mathrm{Y}$ in context $\mathrm{C}$ " implies that institutional facts can be expressed within different media.

As for the type of institutions; cultural cognitive are the cultural aspects of Institutions and the basis of institutional facts, the regulative are institutional facts by themselves and the normative are a middle point between them; both of these have elements of Society and Power.

\section{c) Institutional transmission}

Institutions can endure over time because they can be maintained, reproduced and transmitted by manifesting themselves in different media through speech acts; because the act of transmission implicates a human subject that can interpret, edit, change and put it in different vehicles, and a plurality of human subjects that act as receivers, carriers are not neutral modes of transmission and thus, the nature of the message and the ways in which it is received vary.

Scott (2008) identifies four different kinds of vehicles or carriers:

- Symbolic systems: Rules, values and norms, classifications, representations, frames, schemas, prototypes, and scripts used to guide behavior

- Relational systems: Carriers that rely on interaction among actors across the role system of a society.

- Routines: Structured activities that take the form of habitualized behavior; they rely on patterned behavior that reflects the tacit knowledge of actors.

- Soft routines: Activities encoded into technologies.

- Hard routines: Repetitive patterns of activity.

- Artifact: a material object created or transformed by human activity, under the influence of the physical and cultural environment. The construction of some artifacts can be mandated by regulative authorities, technologies are also shaped by and embody normative processes, and a specific group of ideas can be represented into artifacts.

12 Senn, P. R. (1951), Cigarettes as currency, The Journal of Finance, 6: 329-332. 


\section{d) Levels of institutional analysis}

The impact and usefulness of institutions can be measured from different levels; like with the study of society, two sets of levels of analysis will be offered: one which centers on the receivers of the institutional practice and the other centers on the geographical scope of institutions; these systems of levels of analysis are not mutually exclusive, rather, they overlap. The subjective set of analysis will be slightly modified from that of society and will be comprised by: individuals, organizational subsystems, organizations, organization population, organization field and world system. The geographic set of level analysis is comprised by: community, city, region/federative entity, state, confederation of states and world system.

The individual is the simplest level of analysis available to study institutions; they are the ones that create institutional facts by means of assignation of function to objects and to people. They can have different sets of institutions that influence their behavior: from family life, local or regional culture, national culture, their belonging to organizations acts as an influence; these overlapping institutions are not entirely consistent with one another and this can cause conflicts within the individual when he tries to make sense of the content of two institutions which contrast each other.

Within an organizations there can be fragments of it that can have certain values, norms or culture that can be in harmonious to the whole or partially conflicting with, which comes to be as a consequence of the functions they carry out; at the same time, institutions within organizations can be divergent with those of society in general.

Like the subjective level of analysis, the components of the geographical level of analysis are organizations, a set of organizations or a composite organization which is comprised by many smaller organizations, but what makes them different is that they are bound to a geographical region, unlike subjective levels which can be established in a sector, but can change of location should the need arise. The only exception to these patterns is the world system, which is the largest level, where others are nested within it.

An interesting issue of these multiple levels of institutional analysis is that each of them seeks to influence their component parts by means of power in the three aspects of an institution: norms, values and cultural perception. Of the two sets of level analysis, all of them are in a position to exert influence one over the other; although depending on the circumstances, the environment, allocation of resources and strategic action, some will have more success than others. These connections, relations and struggles among the subjective and geographical levels can be depicted in the following way: 


Organizational

Diagram 4: Levels of institutional analysis

\section{e) Institutions and power}

\section{i) Institutional aspects of power}

The four notions of power can be related with the three elements of institutions stated by Scott; the first and second concepts, which consist on making someone incur or abstain from certain behavior are related to the regulative element of institutions, being that the latter is a system of rules. The third face of power, which consists of making someone do something voluntarily coincides with the normative as a system of rules 
and values that act as guidelines that direct behavior without the mediation of coercion. Finally, the fourth notion of power is related to the cultural cognitive element, seeing that cultural perceptions and scripts are factors that intervene in the social construction of individuals.

These relations are not in reality that clearly defined, as the normative element consists not only of rules, but also of values and serves as a transition between the regulative and cultural cognitive; this means that there is some normative aspect in the first and second and fourth notions, but not enough as to make a direct relation. All of this can be expressed in the following manner:

\begin{tabular}{|l|c|c|c|c|}
\hline & $\begin{array}{c}\text { First notion } \\
\text { of power }\end{array}$ & $\begin{array}{c}\text { Second } \\
\text { notion of power }\end{array}$ & $\begin{array}{c}\text { Third notion } \\
\text { of power }\end{array}$ & $\begin{array}{c}\text { Fourth } \\
\text { notion of } \\
\text { power }\end{array}$ \\
\hline $\begin{array}{l}\text { Regulative } \\
\text { element }\end{array}$ & $\mathrm{X}$ & $\mathrm{X}$ & & \\
\hline $\begin{array}{l}\text { Normative } \\
\text { element }\end{array}$ & & & $\mathrm{X}$ & \\
\hline $\begin{array}{l}\text { Cognitive- } \\
\text { cultural } \\
\text { element }\end{array}$ & & & & $\mathrm{X}$ \\
\hline
\end{tabular}

Diagram 5: institutional aspects of power

ii) Epistemological aspects of power: The relationship between organizations and institutions

Because Institutions are a convergence of Society, Power and Culture, they are background for the exercise of power, the rules that dictate its usage and that also constraint and enable the different individuals and coalitions that aim to attain it. Put forth in a game analogy; Institutions would be the board upon which action develops and the rules that bind strategy and conflict. Just as there are three ways to conceptualize institutions, there are the same number of understand the relations between institutions and organizations.

In the rational perspective, institutions are the rules of the game and organizations are the players, who must act by them, but who also can attempt to change them in their 
favor. ${ }^{13}$ In the normative perspective, the structures, procedures, routines and values of organizations are institutions. As it was mentioned before, Selznick (1981) talks of institutionalization as the infusing of procedures with values beyond the existing technical requirements. The cultural cognitive perspective consists of the cultural processes that take place on the different geographical levels of analysis regarding organizational practices.

\section{Institutional legitimacy}

For their continued functioning, organizations require material resources and technical information, but they also need acceptance and credibility from society. This latter conditions are known as legitimacy, stated by Scott (2008) as "...a generalized perception or assumption that the actions of an entity are desirable, proper or appropriate within some socially constructed system of norms, values, beliefs, and definitions". It serves both an explanatory and a validating function regarding an institutional order; it explains when it gives validity to a group of shared meanings, and it justifies by giving dignity to made decisions, however, the way that it is constructed depends of social concertation.

In the regulatory sense it consists on the conformity to rules, on the normative it also includes a set of internalized moral control and from a cultural cognitive perspective it is the conforming to a common definition of the situation, cultural frame, reference or script. Like the different elements of an institution, the different types of legitimacy differ from each other and can enter into conflict.

\section{Institutional Isomorphism}

Legitimacy influences the assessment of organizational goals due to the existing pressures to conform to social values; this can result in isomorphism, which is the process in which the organizational population or field forces one unit to resemble others that face the same environment. ${ }^{14}$ Powell and DiMaggio (1991) divide institutional isomorphism into three kinds:

\footnotetext{
${ }^{13}$ North, D.C. (2009) Institutions, Institutional Change and Economic Performance (28 ${ }^{\text {th }}$ printing), Cambridge University Press, 3,4 and 5.

${ }^{14}$ Powell W.W., DiMaggio P.J.(Eds.) (1991) The Iron Cage Revisited:Institutional Isomrphism and Collective Rationality in Organizational Fields. In The New Institutionalism in Organizational Analysis, University of Chicago Press, 66.
} 
- Coercive: It results from formal and informal pressures exerted by organizational fields and populations on organizations.

- Mimetic: It is the reaction that a field of population can have to uncertainty, be it real of symbolic.

- Normative: Stems from professionalization, that is, the struggle in which members of an occupation vie to define the conditions and methods for their work and for the creation of more professionals.

DiMaggio and Powell (1991) also issue a set of factors that help predict the presence of isomorphism in a field:

- The greater the extent to which an organizational field is dependent upon a single (or several similar) source(s) of support for vital resources, the higher the level of isomorphism.

- The greater the extent to which the organization transact with the agencies of the state, the greater the extent of isomorphism in the field as a whole.

- The fewer the number of visible alternative organizational models in a field, the faster the rate of isomorphism in that field.

- The greater extent to which technologies are uncertain or goals are ambiguous within a field, the greater the rate of isomorphic change.

- The greater the extent of professionalization in a field, the greater the amount of institutional isomorphic change.

- The greater the extent of structuration in a field, the greater the degree of isomorphism.

On the coercive isomorphic process, there can be first an invitation to change or conform to a practice and as this is adopted it can become less of a choice and involve a display of public force. In obeying the legal mandates, organizations can react in different ways, which can depend on factors such as: existing resources, legitimacy, public opinion, and the ambiguity of law, among others. Although organizations have the need to conform to institutional pressures mimetization might involve fads, fashions and status enhancement.

There are many ways in which organizations can respond to the existing institutional pressures and processes manifested in cultural scripts, system of norms and enforcing organs and agencies. The strategies employed vary on the circumstances and the environment as what is allowed in a field may be prohibited in other, Scott (2008) citing Oliver lists five different tactics:

- Acquiescence or conformity: It can be the mimicking of organizational models, or the compliance of cultural demands or authorities.

- Compromise: It consists of balancing, conciliating and negociating institutional demands by authorities. 
- Avoidance: It is the effort made by organizations to conceal and buffer some of its parts from the institutional pressures to conform.

- Defiance: In this tactic, organizations resist pressures to conform in a public manner.

- Manipulation: Organizations may also seek to change or control the environment in all its manifestations.

Besides the strategic responses of individual organizations, several organizations can band together to respond to institutional pressures, having the potential of changing the demands and norms, redefining their environment and their field. ${ }^{15}$

\section{Conclusions}

FIRST.- Power is the capacity of doing something, which can be set in motion. As social communication it transcends all levels of social interaction, that is, it can be done from a community to a world system.

SECOND.- The exercise of power ranges to the imposition of one will above the other to the manipulation of preferences of a subject; the basis of such exercise of power lies in the shared notions that there are of it.

THIRD.- The context of the exercise power as a coalition/viable system is that of conflict; tactics and strategies are made both to achieve the goals of the system and to maintain its viability.

FOURTH.- Culture is both a cosmovision and a process, that is, it the way in which a collection of individuals see themselves as a group and their environment, thus, it is a repository of information; at the same time it is a process in which such information is obtained.

FIFTH.- Institutions are the interplay of Society, Culture and Power as they comprise the rules, values, and cultural repertoires established as institutional facts that allow their creation and continued existence. Institutions are at the same time a repertoire of information and a set of rules that enable and constrain different actors in their activities.

SIXTH.- Power, Culture and Institutions have static and dynamic aspects: In Power as a capacity of doing something vis a vis its exercise; in Culture, the cosmovision vis a vis the process of culture creation and change and in Institutions as a repertoire of rules, values and shared notions in relation to the roles that they generate to different actors.

\footnotetext{
${ }^{15}$ Talesh S.A. (2009), The Privatization of Public Legal Rights: How Manufacturers Construct the Meaning of Consumer Law, Law \& Society Review, Volume 43, Number 3, 527-530.
} 
SEVENTH.- The ideas of Power, Society and Culture can help to further the understanding of others like Law, Justice, Rule of Law, market, economic efficiency, etc.

\section{Sources}

\section{Electronic}

1. Royal Dictionary of the Spanish Language www.rae.es

2. Dictionary of the French Language http://atilf.atilf.fr/

3. Oxford Dictionary http://oxforddictionaries.com/

\section{Bibliographical}

1. Beer S. (2010) Diagnosing the System for Organizations, John Wiley and Sons.

2. Beer S. (2012) Brain of the Firm, (2nd ed.) John Wiley and Sons.

3. Cyert R.M., March J.G. (2012) A Behavioral Theory of the Firm, (2nd ed.) Blackwell.

4. Dahl, R. (2005) Who Governs? Democracy and Power in an American City, (2nd ed.) Yale University Press.

5. Digeser, P., (1992) The Fourth Face of Power, The Journal of Politics, Vol. 54, No. 4.

6. Livas J. (1988) Cibernetica, Estado y Derecho [Cybernetics, State and Law], Ediciones Guernika.

7. Mancilla Castro R.G. (2012), Derecho adjetivo constitucional [Constitutional adjective law], NOVUM.

8. North, D.C. (2009) Institutions, Institutional Change and Economic Performance ( $28^{\text {th }}$ printing), Cambridge University Press.

9. Scott W. R. (2008) Institutions and Organizations, Sage.

10. Senn, P. R. (1951), Cigarettes AS CURREnCy, The Journal of Finance.

11. Powell W.W., DiMaggio P.J.(Eds.) (1991) The Iron Cage Revisited:Institutional Isomrphism and Collective Rationality in Organizational Fields. In The New Institutionalism in Organizational Analysis, University of Chicago Press.

12. Searle J.R. (2010) Making the social world, Oxford University Press. 
Roberto Gustavo Mancilla

13. Selznick P., Broom L., Broom Darroch D. (1981), Sociology, (7th ed.) Harper and Row.

14. Talesh S.A. (2009), The Privatization of Public Legal Rights: How Manufacturers Construct the Meaning of Consumer Law, Law \& Society Review, Volume 43, Number 3. 